(C) Dereito Vol.27, nºXT:97-110 (Xaneiro-Decembro, 2018) • ISSN 1132-9947

\title{
ÁMBITO SUBJETIVO DE APLICACIÓN: LA PROBLEMÁTICA DE LOS ENTES SUJETOS
}

Subjective ambit of application: the problem of subjects

DOI: http://dx.doi.org/10.15304/dereito.27.Ext.5787

ANA MARÍA LÓPEZ GUIZÁN

Letrada del Consello Consultivo de Galicia

Comisión de Transparencia de Galicia

aguizan@ccgalicia.es

\section{Resumen}

El presente estudio analiza las distintas entidades sujetas a la Ley $1 / 2016$, de 18 de enero, de transparencia y buen gobierno, las obligaciones de publicidad activa aplicables a cada una de ellas, la obligación de suministrar información a cargo de personas privadas, así como las dificultades de aplicación de la ley en el caso de algunas entidades sujetas.

Palabras clave: Ámbito de aplicación, Entidades sujetas, Obligaciones de publicidad activa, Obligación de suministrar información.

\section{Abstract}

This study analyzes the different entities subject to Law $1 / 2016$, of January 18, transparency and good governance, the obligations of active advertising applicable to each of them, the obligation to provide information by private persons, as well as the difficulties of applying the law in the case of some subject entities.

Keywords: Scope of application, Entities subject, Obligations of active advertising, Obligation to provide information.

\section{SUMARIO}

1. INTRODUCCIÓN.;- 2. EL SECTOR PÚBLICO AUTONÓMICO DE GALICIA.;- 3. LAS UNIVERSIDADES DEL SISTEMA UNIVERSITARIO DE GALICIA.;- 4. LAS CORPORACIONES DE DERECHO PÚBLICO.;- 5. EL PARLAMENTO DE GALICIA, EL CONSELLO CONSULTIVO DE GALICIA, EL VALEDOR DO POBO, EL CONSELLO DE CONTAS, EL CONSELLO ECONÓMICO Y SOCIAL, EL CONSELLO DE RELACIONES LABORALES Y EL CONSELLO DE LA CULTURA GALEGA.;- 6. OTROS ENTES CREADOS ESPECÍFICAMENTE PARA SATISFACER NECESIDADES DE INTERÉS GENERAL QUE NO TENGAN CARÁCTER INDUSTRIAL O MERCANTIL.;- 7. LAS ASOCIACIONES CONSTITUIDAS POR LAS ENTIDADES SUJETAS A LA LEI.;- 8. LOS PARTIDOS POLÍTICOS, LOS SINDICATOS Y LAS ORGANIZACIONES EMPRESARIAIS.;- 9. LAS ENTIDADES PRIVADAS OBLIGADAS A SUMINISTRAR INFORMACIÓN.;- 10. BIBLIOGRAFÍA

Recibido: 10/12/2017. Aceptado: 09/09/2018. 


\section{INTRODUCCIÓN}

El ámbito de aplicación de la LGT, como ocurre con la normativa estatal contenida en la LETAI, no se limita a la administración pública, tal y como se ha entendido tradicionalmente a esta estructura vicarial, sino que, muy probablemente por el contexto socioeconómico del momento de aprobación de ambas leyes, marcado por una fuerte crisis económica y social y con una creciente exigencia de rendición de cuentas a los poderes públicos, el legislador optó por extender la regulación de la materia a los poderes públicos en sentido amplio y a otras entidades, de carácter eminentemente privado que, por su relevancia institucional, por su colaboración con las administraciones públicas o por ser receptoras de fondos públicos, merecían también estar sujetas a tal régimen.

Debe notarse que el ámbito de aplicación de la LETAI y, como no podía ser de otro modo, también de la LGT, es más amplio que el previsto en el Convenio Europeo sobre Acceso a los Documentos Públicos, adoptado por el Consejo de Europa el 27 de noviembre de 2008, y en la normativa de nuestro entorno europeo inmediato.

Esta necesidad de establecer un amplio ámbito de aplicación de la nueva regulación se planteó ya en el trámite de consulta pública del anteproyecto de la LETAI, que inicialmente circunscribía su ámbito subjetivo sólo al sector público, reiterándose tal necesidad también en la tramitación parlamentaria de la ley hasta el punto de que todos los grupos parlamentarios, sin excepción, formularon propuestas a la regulación propuesta por el Gobierno. Como señala GUICHOT ${ }^{1}$, la definición de este ámbito fue "objeto de modificaciones relevantes en un proceso impulsado en buena medida por los muchos episodios de corrupción que asolan la vida pública y que se desarrolla además sobre el telón de fondo de una profunda y preocupante desafección ciudadana hacia las instituciones públicas".

Atendiendo a estas circunstancias y demandas ciudadanas, la LETAI incluyó en su articulado, no sólo al sector público entendido de forma amplia (art. 2), sino también a entidades con funciones de relevancia constitucional tradicionalmente perceptoras de fondos públicos (letra a del art. 3), a entidades privadas que reciban subvenciones públicas con ciertos límites (letra b del art. 3), así como también a entidades privadas que presten servicios púbicos o ejerzan potestades administrativas (art. 4).

Esta delimitación, dado el carácter básico de la LETAI (disposición final octava), ha sido respetada por el legislador autonómico en la LGT, cuyos arts. 3 y 4 establecen el ámbito de aplicación de las disposiciones relativas a la transparencia de la actividad pública, recogidas en el Título I de la ley.

\section{EI SECTOR PÚBLICO AUTONÓMICO DE GALICIA}

El art. 2.1 de la LETAI sujetó a sus prescripciones tanto a las administraciones de las comunidades autónomas (letra a), como a las

\footnotetext{
${ }^{1}$ E. GUICHOT, Transparencia y buen gobierno, Aranzadi, Pamplona, 2014.
} 
entidades con personalidad jurídica propia vinculadas o dependientes de ellas (letra d).

En su desarrollo, respetando la normativa estatal, el art. 3.1, letra a), de la LGT establece que las disposiciones de la ley relativas a la transparencia de la actividad pública serán de aplicación "al sector público autonómico, integrado, de acuerdo con la Ley 16/2010, de 17 de diciembre, de organización y funcionamiento de la Administración general y del sector público autonómico de Galicia, por la Administración general de la Comunidad Autónoma de Galicia y las entidades instrumentales de su sector público".

Se establece, por tanto, la sujeción a las disposiciones legales en materia de transparencia, del sector público autonómico tal y como este se delimita en la Ley 16/2010, de 17 de diciembre, considerando que las entidades que integran este sector público, de acuerdo con el art. 4 de dicha ley, "sirven con objetividad a los intereses generales y actúan con sometimiento pleno a la Constitución, al Estatuto de Autonomía, a la ley y al resto del ordenamiento jurídico", y que el art. 3 de la Ley 40/2015, de 1 de octubre, de Régimen Jurídico del Sector Público, dispone que las Administraciones Públicas deberán respetar en sus actuaciones y relaciones, entre otros, los principios de participación, objetividad y transparencia en la actuación administrativa.

Cuál sea la configuración del sector público autonómico de Galicia es una cuestión resuelta en el ya citado art. 4 de la Ley 16/2010, de 17 de diciembre, que incluye en el mismo tanto la Administración General de la Comunidad Autónoma de Galicia, organizada en consejerías según el art. 23, como las entidades integrantes del sector público autonómico. Dentro de estas entidades públicas instrumentales, se encuentran, de acuerdo con el art. 45 de la Ley 16/2010, de 17 de diciembre, una variada tipología de entes, como son:

1) Los organismos autónomos, definidos como las entidades públicas instrumentales cuya organización y funcionamiento se regulan por el derecho administrativo, y que se someten al derecho privado sólo en aquellos casos en que corresponda de acuerdo con la normativa general aplicable. Estas entidades, de acuerdo con su normativa específica, pueden ejercer actividades de intervención, fomento, gestión de servicios públicos o apoyo a la función administrativa en régimen de descentralización funcional (art. 68).

2) Las agencias públicas autonómicas, en cuanto entidades a las que, para el cumplimiento de programas específicos correspondientes a políticas públicas de la Administración general de la Comunidad Autónoma, se les encomienda la realización de actividades en régimen de descentralización funcional y gestión por objetivos (art. 74).

3) Las entidades públicas empresariales, que son entes instrumentales a los que se les encomienda la realización, conforme a criterios de gestión empresarial, de actividades prestacionales, de gestión de servicios públicos o de producción de bienes de interés público susceptibles de contraprestación (art. 89). 
4) Los consorcios constituidos por la Administración General de la Comunidad Autónoma de Galicia mediante convenio con otras Administraciones Públicas, para la gestión de servicios de su competencia o para la consecución de fines de interés común, así como con entidades privadas sin ánimo de lucro que persigan fines de interés público concurrentes con los de la Xunta de Galicia, para la realización de éstos. Hay que matizar que la configuración de tales consorcios como autonómicos y, por tanto, como sujetos a la LGT se ciñe a aquellos en los que la Administración General de la Comunidad Autónoma, directamente o a través de sus entidades públicas instrumentales, hubiese aportado mayoritariamente los medios necesarios para su constitución y funcionamiento o se hubiese comprometido, en el momento de su constitución, a financiarlos mayoritariamente, siempre que la actuación de sus órganos de dirección y gobierno esté sujeta al poder de decisión de la Administración general de la Comunidad o de otra entidad pública instrumental (art. 95).

5) Las sociedades mercantiles públicas autonómicas, definidas como las sociedades mercantiles, cualquiera que sea la forma que adopten, en cuyo capital social sea mayoritaria la participación directa o indirecta de la Administración general de la Comunidad Autónoma de Galicia y de las entidades instrumentales reguladas en la Ley 16/2010, de 17 de diciembre (art. 102).

6) Las fundaciones del sector público autonómico, que son aquellas fundaciones en las que concurran cualquiera de las siguientes circunstancias:

a) Que se constituyan, directa o indirectamente, con una aportación mayoritaria o exclusiva de la Administración general de la Comunidad Autónoma de Galicia y/o de las entidades integrantes del sector público autonómico.

b) Que su patrimonio fundacional, con carácter de permanencia, esté formado en más de un $50 \%$ por bienes y derechos aportados o cedidos por las referidas entidades.

c) Que sus ingresos provengan mayoritariamente de los presupuestos de la Comunidad Autónoma siempre que, en este caso, se posea la mayoría o se ejerza control análogo sobre sus órganos de gobierno y dirección (art. 113).

Hay que aclarar que la Ley $16 / 2010$, de 17 de diciembre, excluye de la categoría de fundaciones del sector público autonómico a aquellas fundaciones que simplemente reciban financiación de la Administración General o de las entidades instrumentales del sector público autonómico. Estas fundaciones no estarán sujetas al régimen de publicidad activa que la LGT prevé para el sector público autonómico, pero sí al régimen de publicidad activa previsto para las entidades que reciban subvenciones públicas conforme al art. 3, letra b), de la LETAI.

A la Administración general de la Comunidad Autónoma y a las entidades instrumentales del sector público autonómico les es de aplicación con una especial intensidad el régimen de publicidad activa previsto en la LGT, 
pues una y otras están obligadas a publicar toda la información relacionada en los arts. 7 a 17 de la ley.

Mención específica merece la información de relevancia jurídica, la información en materia patrimonial y sobre encomiendas de gestión y encargos a medios propios, a la que se refieren los arts. 9, 12 y 16, cuya publicación la LGT sólo exige al sector público autonómico. De esta forma, la información, de publicación exclusivamente obligatoria para el sector público autonómico, comprende, en el ámbito de sus competencias, la siguiente:

a) La relación de la normativa vigente en su versión consolidada.

b) Los textos de las resoluciones judiciales firmes que afecten a la vigencia o interpretación de las normas dictadas por la Administración pública competente.

c) La relación circunstanciada y motivada de los procedimientos de elaboración de anteproyectos de ley y de disposiciones administrativas de carácter general que estén en tramitación, a partir del momento en el que se produzca la aprobación del anteproyecto, indicando su objeto y estado de tramitación, así como la posibilidad que tienen las personas de remitir sugerencias y la forma de hacerlo.

Respecto a la publicación de esta relación circunstanciada y motivada de los procedimientos de elaboración de anteproyectos de ley y de disposiciones administrativas de carácter general que estén en tramitación, es preciso recordar que tal obligación fue ya establecida de una forma pionera para los anteproyectos de disposiciones administrativas de carácter general en la Ley 4/2006, de 30 de junio, de transparencia y buenas prácticas de la Administración pública gallega $y$, luego, en el art. 41.4 de la Ley 16/2010, de 17 de diciembre, al regular la fase inicial del procedimiento de elaboración de las disposiciones administrativas de carácter general.

d) La relación de bienes de interés cultural.

e) El número de vehículos de los que es titular o arrendatario.

f) Respecto a las encomiendas de gestión y encargos a medios propios, el porcentaje de actividad realizada por el medio propio a favor de los entes de control.

\section{LAS UNIVERSIDADES DEL SISTEMA UNIVERSITARIO DE GALICIA}

El art. 3.1, letra b), de la LGT incluye en su ámbito de aplicación a las "universidades del Sistema Universitario de Galicia y a las entidades vinculadas o dependientes de las mismas".

La Ley 6/2013, de 13 de junio, del Sistema Universitario de Galicia, en su art. 3.1, integra en el Sistema Universitario de Galicia a la Universidad de A Coruña, a la Universidad de Santiago de Compostela y a la Universidad de Vigo así como, en su caso, a aquellas que sean creadas o reconocidas por ley del Parlamento de Galicia.

Por tanto, se integran en el Sistema Universitario de Galicia, tanto las universidades públicas creadas por ley como las universidades privadas por ella reconocidas (art. 12), siendo así que, dado que el art. 3.1 b) de la 
LGT no distingue al aludir genéricamente a las "universidades del Sistema Universitario de Galicia", podría entenderse que en esta letra b) del art. 3.1 también se incluirían las universidades privadas. Con ello, es importante señalar, se produce una ampliación importante del ámbito de aplicación de la LGT respecto de su homóloga estatal, pues esta última sólo incluye a las universidades públicas (art. 2.1, b).

La única razón que podría justificar tal inclusión sería el cometido de tales universidades que, junto con las públicas, realizan, como señala el art. 3.2 de la Ley 6/2013, de 13 de junio, "el servicio público de la enseñanza superior universitaria en Galicia mediante el ejercicio de la docencia, el estudio, la investigación, la creación, la difusión y la transferencia de conocimiento".

Sin embargo, parece excesivo sujetar a las universidades privadas integrantes del Sistema Universitario de Galicia a las previsiones de la LGT, equiparándolas a todos los efectos a las universidades públicas, especialmente si se considera que en la ley estatal las universidades públicas se configuran como administraciones públicas (art. 2.2 de la LETAI).

En particular, las universidades integrantes del Sistema Universitario de Galicia tienen la obligación de publicar la información institucional, organizativa y de planificación relacionada en el art. 7 de la LGT, la información sobre las relaciones con la ciudadanía a la que se refiere el art. 8, la información en materia de personal y económica, presupuestaria y estadística de los arts. 10 y 11, la información contractual del art. 13, y la información sobre concesión de servicios públicos y subvenciones que prevén los arts. 14 y 17 de la LGT.

Pues bien, de una somera lectura de la información relacionada en estos artículos de la LGT se desprende el exceso que implicaría someter a las universidades privadas integrantes del Sistema Universitario de Galicia a un régimen de publicidad activa idéntico al de las universidades públicas. Y ello porque la mayoría de sus previsiones (piénsese en la información en materia de contratación pública a que se refiere el art. 13 de la ley, en la información específica en materia de subvenciones del art. 17 o en muchos de los aspectos de la información en materia de personal del art. 10 o de la económica y presupuestaria del art. 11) tienen un carácter imposible en entidades de naturaleza privada como son las universidades privadas, pues la LGT, como la ley estatal, parte en muchos de sus preceptos de la naturaleza jurídico pública de los entes obligados o de su financiación mayoritariamente pública. $E$, incluso, en aquellos aspectos que sí podrían aplicarse a tales universidades privadas, sujetarlas a la obligación de publicitar aquellos aspectos, equiparándolas a las universidades públicas, aún bajo el prisma del servicio público que prestan, también parece excesivo (por ejemplo, los permisos para la realización de funciones sindicales del art. 10, letra c), o la información básica sobre su financiación del art. 11, letra a).

En este sentido hubiese sido más coherente con la filosofía de la regulación de transparencia bien dejar a las universidades privadas integrantes del Sistema Universitario de Galicia fuera de su ámbito de 
aplicación, bien a lo sumo sujetarlas a una genérica obligación de suministro de información similar a la prevista en los arts. 4 de la LETAI y 4 de la LGT, toda vez que esas universidades, como las públicas, prestan el servicio público de la enseñanza superior en Galicia.

\section{LAS CORPORACIONES DE DERECHO PÚBLICO}

El art. 3.1, letra c), de la LGT incluye en el ámbito de aplicación de las previsiones relativas a la transparencia de la actividad pública a las "corporaciones de Derecho público que desarrollen su actividad exclusivamente en el ámbito territorial de la Comunidad Autónoma de Galicia, en lo relativo a sus actividades sujetas a derecho administrativo". De nuevo nos encontramos ante un fiel trasunto del art. 2.1, letra e), de la LETAI, que incluyó en su ámbito de aplicación a las "corporaciones de Derecho Público, en lo relativo a sus actividades sujetas a Derecho Administrativo".

Al respecto debe notarse que la sujeción de las corporaciones de Derecho Público a la LGT se ciñe a sus actividades sujetas a Derecho Administrativo, quedando al margen de la ley sus actividades sujetas al Derecho Privado. Esta disociación de la actividad de las corporaciones de Derecho Público responde a la doble naturaleza de estas corporaciones, ya señalada tempranamente por el Tribunal Constitucional en la Sentencia 76/1983, de 5 de agosto, al concurrir en las mismas, por un lado, una dimensión privada en cuanto tienen como función propia la prestación de servicios a sus miembros y la representación de sus intereses económicos y corporativos; y, por otro, una dimensión pública, al imponer la ley su constitución obligatoria, atribuirles el carácter de órganos de consulta de las administraciones, someterlas a la tutela de estas últimas y reconocerles la posibilidad de que ostenten competencias administrativas por atribución legal o por delegación de las administraciones públicas.

Precisamente el desarrollo de estas funciones públicas bajo la tutela de las administraciones públicas parece ser la razón de la inclusión de estas entidades en el ámbito de aplicación de la LGT, especialmente si se considera que estas corporaciones se financian mayoritariamente con aportaciones de sus miembros, y no con fondos públicos, de manera que la regla follow the money o la máxima de control del dinero público no justificaría tal inclusión. Nótese en este sentido que el art. 5.1 de la LETAI dispone que todos los sujetos incluidos en el ámbito de aplicación de la ley en materia de transparencia de la actividad pública "publicarán de forma periódica y actualizada la información cuyo conocimiento sea relevante para garantizar la transparencia de su actividad relacionada con el funcionamiento y control de la actividad pública".

Sin embargo, aquella inclusión de las corporaciones públicas limitada a las actividades sujetas a Derecho Administrativo, no deja de plantear problemas en la práctica, pues algunas de las previsiones de publicidad activa previstas para todos los sujetos incluidos en el art. 3.1 de la LGT, resultan difícilmente aplicables a estas corporaciones en cuanto diseñadas prima facie para las administraciones públicas. Ilustrativo de este extremo es que a estas entidades les resultan de aplicación las previsiones sobre 
publicidad activa recogidas en los arts. 7, 8, 10 y 11 de la LGT, pero muchas de las recogidas en los arts. 10, relativas a la información en materia de personal, y 11 , relativas a la información económica, presupuestaria y estadística, resultan de muy difícil aplicación a las mismas. Y, por otro lado, en otros de aplicación clara, es complicado deslindar las actividades sujetas a Derecho Administrativo del resto, como es el supuesto de su estructura organizativa o las retribuciones percibidas anualmente por los máximos responsables de las entidades (art.s 6.1 y $8.1 \mathrm{f}$ ) de la Ley 19/2013, de 9 de diciembre), que en muchos casos será común para el desarrollo de sus funciones públicas y privadas.

En todo caso, y como sostiene De la Nuez ${ }^{2}$, la sujeción de estas entidades a la LGT constituye un mínimo y nada obsta a que las mismas, voluntariamente, puedan ir más allá de sus obligaciones legales, facilitando información adicional prevista en la ley para otros sujetos.

Así, en el ámbito de los colegios profesionales, debe destacarse que el art. 11 de la Ley 2/1974, de 13 de febrero, de colegios profesionales, establece como las organizaciones colegiales estarán sujetas al principio de transparencia en su gestión, debiendo elaborar al efecto una memoria anual que ha de recoger una amplio elenco de información y hacerse pública a través de la página web en el primer semestre de cada año.

Por último, en lo que se refiere al cumplimiento de las obligaciones de publicidad activa por parte de estas corporaciones, hay que recordar que la disposición adicional tercera de la LETAI prevé que las corporaciones podrán celebrar convenios de colaboración con la administración pública correspondiente 0 , en su caso, con el organismo que ejerza la representación en su concreto ámbito de actividad.

\section{5. el PARLAMENTO DE GALICIA, EL CONSELlO CONSULTIVO DE GALICIA, EL VALEDOR DO POBO, EL CONSELLO DE CONTAS, EL CONSELLO ECONÓMICO E SOCIAL, EL CONSELLO DE RELACIÓNS LABORAIS Y EL CONSELLO DA CULTURA GALEGA}

En una línea muy similar a la de la LETAI, el art. 3.1 de la LGT, en su letra d), incluye en su ámbito de aplicación al Parlamento de Galicia, al Consello Consultivo, al Valedor do Pobo, al Consello de Contas, al Consello Económico e Social, al Consello Galego de Relacións Laborais y al Consello da Cultura Galega, si bien sólo en relación con sus actividades sujetas al Derecho Administrativo y, en todo caso, respecto a sus actos en materia de personal y contratación.

Debe señalarse que esta letra d) del art. 3.1 LETAI recoge órganos de distinta naturaleza al incluir tanto algunos con rango estatutario como el Parlamento de Galicia, el Valedor do Pobo, el Consello de Contas o el Consello da Cultura Galega, como otros órganos sin relevancia estatutaria pero no integrados en el sector público autonómico en sentido formal como son el Consello Consultivo, el Consello Económico e Social y el Consello Galego de Relacións Laborais.

${ }^{2}$ E. DE LA NUEZ SÁNCHEZ-CASCADO, Transparencia y buen gobierno, La Ley, Madrid, 2014 
Respecto a estos últimos órganos sin relevancia estatutaria es preciso advertir que su normativa reguladora les reconoce a todos ellos autonomía funcional, aunque sólo al Consello Consultivo autonomía orgánica (art. 1 de la Ley 3/2014, de 22 de abril, del Consello Consultivo de Galicia), pues el Consello Galego de Relacións Laborais se adscribe orgánicamente a la consellería competente en materia de trabajo (art. 1.3 de la Ley 5/2008, de 23 de mayo, por la que se regula el Consello Galego de Relacións Laborais) y el Consello Económico e Social de Galicia, aunque dotado formalmente de autonomía orgánica, se adscribe a la consellería con competencias en materia de hacienda (art. 3.2 e 3 de la Ley 6/1995, de 28 de junio, por la que se crea el Consejo Económico e Social).

Es así que resulta cuestionable la no equiparación, a efectos de la LGT, de estos dos últimos órganos, Consello Económico e Social y Consello Galego de Relacións Laborais, con el sector público autonómico al que se refiere la letra a) del art. 3.1 de la LGT, en cuanto entes ambos adscritos orgánicamente a la Administración general de la Comunidad Autónoma Gallega.

Esta inclusión, es necesario señalar, evitaría la disfunción que genera el art. 37 de la LGT que, al regular el ámbito de aplicación de la regulación de los altos cargos, lo circunscribe a aquellos cargos que tengan tal naturaleza en el seno de la Administración general y del sector público (art. 37.1, letras a) a e) y al presidente o presidenta del Consello Económico e Social (art. 37.1, letra f), estando, por tanto excluido, el presidente o presidenta del Consello Galego de Relacións Laborais. Dado que uno y otro órgano no se incluyen formalmente en el sector público autonómico a los efectos del art. 3.1 de la LGT y dado que ambos tienen una configuración institucional similar, no se entiende que el presidente o presidenta del Consello Económico e Social esté sujeto a las previsiones de la LGT sobre altos cargos, y el del Consello Galego de Relacións Laborais no.

Por otro lado, la sujeción de todos estos órganos a la LGT en materia de publicidad activa implica la aplicación de las previsiones contenidas en los arts. $7,8,10,11,13,14$ y 17, con una importante modulación, que es que sólo se aplicarán "en relación con sus actividades sujetas a Derecho Administrativo $y$, en todo caso, respecto de sus actos en materia de personal y contratación".

Este último inciso " $y$, en todo caso, respecto de sus actos en materia de personal y contratación" constituye una novedad relevante respecto a la regulación contenida en la normativa básica estatal, que simplemente alude a la sujeción de estas instituciones en relación con sus actividades sujetas a Derecho Administrativo. Este aspecto fue ampliamente cuestionado por la doctrina ya que suponía dejar fuera del ámbito de aplicación de la ley buena parte de los aspectos vinculados al personal laboral y a la contratación en régimen de derecho privado de tales órganos, y esto porque sólo los llamados "actos separables" de la contratación laboral y privada, en cuanto sujetos a la regulación administrativa, quedaban incluidos en las obligaciones de transparencia activa de tales sujetos. 
En este sentido la LGT, a diferencia de su homóloga estatal, integra en la publicidad activa de estos órganos a todos sus actos en materia de personal y contratación, estén sujetos a aquella normativa administrativa o al régimen de Derecho Privado, con lo que se produce una importante ampliación de la publicidad activa de aquellos, que redunda, en definitiva, en una mayor transparencia en su gestión.

\section{OTROS ENTES CREADOS ESPECÍFICAMENTE PARA SATISFACER NECESIDADES DE INTERÉS GENERAL QUE NO TENGAN CARÁCTER INDUSTRIAL O MERCANTIL}

El art. 3.1, letra e), de la LGT incluye en su ámbito de aplicación a todos los demás entes, organismos o entidades con personalidad jurídica propia distintos de los expresados en las restantes letras del artículo, que fuesen creados específicamente para satisfacer necesidades de interés general que no tengan carácter industrial o mercantil, siempre que uno o varios sujetos de los indicados en este mismo art. 3.1 financien mayoritariamente su actividad, controlen su gestión o nombren a más de la mitad de los miembros de su órgano de administración, dirección o vigilancia.

Se trata, en definitiva, de incorporar en el ámbito de aplicación de la ley, una cláusula residual que dé cabida a todos aquellos entes con personalidad jurídica propia que, teniendo por objeto satisfacer necesidades de interés general que no tengan carácter industrial o mercantil, y sin integrarse en las estructuras formales de la Ley 16/2010, de 17 de diciembre, tengan una financiación mayoritariamente pública o una responsabilidad pública en su gestión. Se combinan con ello dos criterios de sujeción a la normativa de transparencia: por un lado, la regla follow the money o control del gasto público y, por otro, la responsabilidad pública en la gestión aunque ésta tenga lugar a través de personificaciones instrumentales atípicas.

Es el caso de entes como el ente público Portos de Galicia creado mediante la Ley 5/1994, de 29 de noviembre, o del ente público Instituto Enerxético de Galicia creado por la Ley 3/1999, de 11 de marzo.

Las obligaciones de publicidad activa de estas entidades son las recogidas en los arts. 7, 8, 10 y 11 de la LGT. En este punto hubiese sido deseable que la ley también las sujetase a las obligaciones de publicidad activa que, en materia de contratación y subvenciones, establecen los arts. 13 y 17 como adicionales a las previstas en la normativa básica; y ello porque, a pesar de sus peculiaridades, estas entidades no dejan de ser una manifestación típica de la descentralización funcional de la Administración pública gallega, debiendo aproximarse el nivel de exigencia de transparencia que les es exigible al previsto para aquélla.

\section{LAS ASOCIACIONES CONSTITUIDAS POR LAS ENTIDADES SUJETAS A LA LEY}

El art. 3.1, letra f), de la LGT incluye en el ámbito de aplicación de la ley a las asociaciones constituidas por los entes, organismos o entidades anteriores. 
El régimen de publicidad activa de estas asociaciones es el previsto en los arts. 7, 8, 10 y 11 de la LGT.

En otro orden de cosas, es importante destacar que la LETAI, en su art. 2.1 , letra i), incluyó en este punto a los órganos de cooperación previstos en el art. 5 de la vieja Ley 30/1992, de 26 de noviembre, que aludía a las conferencias sectoriales y otros órganos de cooperación de la Administración del Estado y de las administraciones de las comunidades autónomas.

En la actualidad debe notarse que estos órganos de cooperación de la Administración del Estado y de las administraciones de las comunidades autónomas, se regulan en el capítulo III del Título III de la Ley 40/2015, de 1 de octubre, de régimen jurídico del sector público. Pero, a mayores, la Ley 40/2015, de 1 de octubre, prevé órganos de cooperación entre las comunidades autónomas y las entidades locales; en concreto, el art. 154.1 , letra b), de esta ley prevé la existencia de comisiones territoriales formadas por representantes de las comunidades autónomas y representantes de las entidades locales, para mejorar la coordinación de la prestación de los servicios, prevenir duplicidades y mejorar la eficiencia y calidad de los servicios, cuando la proximidad territorial o la concurrencia de las funciones administrativas así lo requiera.

Es importante advertir que la normativa no prevé la sujeción de estas comisiones territoriales a ningún régimen de publicidad activa, al no estar incluidas en la literalidad del art. 2.1, letra i), de la LETAI, ni tampoco en la LGT.

\section{LOS PARTIDOS POLÍTICOS, LOS SINDICATOS $Y$ LAS ORGANIZACIONES EMPRESARIALES}

El art. 3.2 de la LGT establece que los partidos políticos, las organizaciones sindicales, las organizaciones empresariales y las entidades privadas perceptoras de fondos públicos a que se refiere el art. 3 de la LETAI, cuando reciban fondos del sector público autonómico, darán cumplimiento a sus obligaciones de publicidad activa en el Portal de Transparencia.

Un adecuado entendimiento de este precepto exige considerar el art. 3 de la LETAI, que sujeta a las disposiciones de la ley en materia de publicidad activa, por un lado, a los partidos políticos, organizaciones sindicales y organizaciones empresariales $y$, por otro, a las entidades privadas que perciban durante el período de un año ayudas o subvenciones públicas en una cuantía superior a $100.000 €$ o cuando al menos el $40 \%$ del total de sus ingresos anuales tengan carácter de ayuda o subvención pública, siempre que alcancen como mínimo la cantidad de 5.000 €.

La transcripción del precepto básico no es irrelevante en lo que se refiere a los partidos políticos, organizaciones sindicales y empresariales porque, del contraste de ambos preceptos, resulta que estas entidades están sujetas a las obligaciones de publicidad activa previstas en la normativa estatal y, si además perciben fondos del sector público autonómico, habrán de cumplir estas obligaciones en el Portal de Transparencia y 
Gobierno abierto previsto en el art. 29 de la ley, al igual que las entidades privadas perceptoras de ayudas o subvenciones públicas autonómicas.

Por otro lado, la disímil sujeción de los partidos políticos, sindicatos y organizaciones empresariales y de las entidades privadas perceptoras de ayudas o subvenciones públicas en la ley básica estatal (la sujeción de los primeros no se condiciona a la percepción de fondos públicos) pone de relieve que el motivo de la inclusión de los primeros en una normativa como la de transparencia, con una vocación inicial puramente administrativa, se debe a un doble orden de motivaciones: por un lado, dado que estas entidades tienen una financiación pública importante, la ya mencionada regla follow the money, que exige someter a estas entidades a un régimen de transparencia y rendición de cuentas $y$, por otro, la relevancia de sus funciones desde un punto de vista público y constitucional. En cambio, para el supuesto de las entidades privadas previstas en la letra b) del art. 3 de la LETAI, el único criterio ha sido el control del gasto público, y limitado cuantitativamente a fin de evitar que todas aquellas entidades que perciban algún tipo de ayuda o subvención se tengan que someter al régimen de publicidad activa previsto en la ley.

En cuanto a las obligaciones de publicidad activa establecidas para los sujetos del art. 3.2 de la LGT, dado que la LGT no contiene ninguna previsión adicional al respecto, éstas son las recogidas en la LETAI, que genéricamente las somete al régimen de publicidad activa recogido en el Capítulo II de su Título II para aquellas entidades que no tienen el carácter de administración pública. Pero, lógicamente, esta sujeción debe entenderse circunscrita a aquellos aspectos relacionados con el "control de los asuntos públicos", tal y como establece el art. 6.1 de la LGT cuando dispone que "Se entiende por publicidad activa el compromiso de los sujetos comprendidos en los apartados 1 y 2 del art. 3 de publicar por propia iniciativa y de forma periódica, actualizada, clara, veraz, objetiva y fácilmente accesible toda aquella información relevante relativa a su funcionamiento, como medio para fomentar el ejercicio por parte de la ciudadanía de su derecho fundamental a la participación y al control sobre los asuntos públicos".

Así, tal y como entendió el Consejo de Transparencia y Buen Gobierno en su criterio interpretativo 3/2015, a estas entidades les es de aplicación el art. 6.1 de la LETAI, en lo relativo a su estructura, organización y funciones, y el art. 8 en su totalidad, si bien el art. 8.2 de la LETAI, contiene unas matizaciones que son de aplicación a los contratos, convenios y subvenciones de carácter privado pues estas entidades únicamente deberán publicar los contratos y los convenios celebrados con una administración pública y las subvenciones cuando el órgano concedente también sea una administración pública.

Por otro lado, el cumplimiento de las obligaciones de publicidad activa de los sujetos previstos en el art. 3.2 de la LGT, como ya se señaló, deberá verificarse, cuando reciban fondos del sector público autonómico, en el Portal de Transparencia y Gobierno Abierto. Ello no obsta a que estas entidades también deban publicar la información correspondiente en su 
sede electrónica o página web, como se exige con carácter general para los sujetos obligados en los artss 5.4 de la LETAI, y 6.4 de la LGT.

Finalmente, el art. 5.4 de la Ley estatal 19/2013, de 9 de diciembre, permite que las entidades sin ánimo de lucro que persigan exclusivamente fines de interés social o cultural y cuyo presupuesto sea inferior a $50.000 €$, puedan cumplir sus obligaciones en materia de publicidad activa utilizando los medios electrónicos puestos a su disposición por la Administración pública de la que provenga la mayor parte de las ayudas o subvenciones públicas percibidas.

Se trata, en definitiva, de facilitar a estas entidades sin ánimo de lucro y bajo presupuesto el cumplimiento de las obligaciones legales de publicidad activa, poniendo a su disposición los medios de la Administración pública concedente de las ayudas o subvenciones públicas.

\section{LAS ENTIDADES PRIVADAS OBLIGADAS A SUMINISTRAR INFORMACIÓN}

La LETAI estableció en su art. 4 como las personas físicas y jurídicas distintas de las referidas en sus arts. 2 y 3 que presten servicios públicos o ejerzan potestades administrativas, estarán obligadas a suministrar a la administración, organismo o entidad de las previstas en el art. 2.1 a la que se encuentren vinculadas, previo requerimiento, toda la información necesaria para el cumplimiento por aquéllos de las obligaciones en materia de transparencia de la actividad pública. Así mismo el art. 4 aclara que esta obligación se extenderá a los adjudicatarios de los contratos del sector público en los términos previstos en el respectivo contrato.

El art. 4 de la LGT recoge estas previsiones extendiéndolas en su apartado 2 también a las personas físicas o jurídicas beneficiarias de subvenciones, sin recoger distinción alguna por razón de la cuantía percibida. Por tanto, para estar sujeta a las obligaciones de publicidad activa, la persona beneficiaria de las ayudas ha de ser una persona jurídica ("entidades privadas" refieren los arts. 3 de la LETAI y 3.2 de la LGT) y haber recibido en el período de un año ayudas o subvenciones en una cuantía superior a $100.000 €$ o cuando al menos el $40 \%$ del total de sus ingresos anuales tengan carácter de ayuda o subvención pública, siempre que alcance como mínimo, la cantidad de 5.000€. En cambio, para estar sujeta a la obligación de suministrar información que prevé el art. 4 de la LGT, es indiferente que se trate de una persona física o jurídica, y también la cuantía percibida.

El fundamento del establecimiento de estas obligaciones, como apuntó el dictamen del Consejo de Estado 707/2012, de 19 de julio, es la especial vinculación de los sujetos obligados con las administraciones públicas así como la naturaleza de las funciones que realizan y de las potestades que pueden ejercer. Y su finalidad, como señala De la $\mathrm{Nuez}^{3}$, es permitir a las Administraciones Públicas cumplir con las obligaciones legales de

${ }^{3}$ E. DE LA NUEZ SÁNCHEZ-CASCADO, Transparencia y buen gobierno, La Ley, Madrid, 2014. 
publicidad activa, imponiendo a aquellas personas obligaciones frente a aquéllas, y no frente a la ciudadanía.

Por otro lado, la LGT dispone que las bases reguladoras de las subvenciones así como la documentación contractual o los negocios jurídicos que instrumenten la prestación de los servicios públicos o el ejercicio de potestades públicas, recogerán expresamente esta obligación de suministrar información y las consecuencias de su incumplimiento. Y añade que reglamentariamente se establecerá el procedimiento que es necesario seguir para el cumplimiento de esta obligación, así como las multas coercitivas aplicables en los supuestos en los que el requerimiento de la información no sea atendido en plazo. Establece al mismo tiempo que la multa de 100 a $1.000 €$ será reiterada por periodos mensuales hasta su cumplimiento y que el total de la multa no podrá exceder del $5 \%$ del contrato, subvención o instrumento administrativo que habilite para el ejercicio de las funciones públicas o la prestación de servicios y en el supuesto de que en dicho instrumento no figure una cuantía concreta, la multa no excederá de los $3.000 €$.

Estas previsiones, no recogidas en la normativa estatal, merecen un juicio muy positivo pues vienen a solventar la cuestión ya apuntada por el Consejo de Estado relativa a la determinación de las consecuencias del incumplimiento de la obligación de suministrar información. En cambio, dado que el procedimiento para la exigencia de esta obligación y para la imposición de multas en caso de su incumplimiento se remiten a un ulterior desarrollo reglamentario, hubiese sido deseable que en las disposiciones finales de la LGT se hubiese establecido un plazo máximo al efecto pues, en ausencia de tal normativa reglamentaria, será difícil de materializar el cumplimiento de tales obligaciones, e imposible la imposición de multas en caso de incumplimiento.

\section{BIBLIOGRAFÍA}

GUICHOT, E., Transparencia y buen gobierno, Aranzadi, Pamplona, 2014. DE LA NUEZ SÁNCHEZ-CASCADO, E., Transparencia y buen gobierno, La Ley, Madrid, 2014. 